\title{
DESSULFURIZAÇÃO ADSORTIVA DO CONDENSADO ORIUNDO DA PIRÓLISE DE PNEUS INSERVÍVEIS
}

\author{
T. G. NOYA ${ }^{1}$, R. B. TORRES ${ }^{1}$ e R. G. SANTOS ${ }^{1}$ \\ ${ }^{1}$ Centro Universidade da FEI, Departamento de Engenharia Química \\ E-mail para contato: rgsantos@fei.edu.br
}

\begin{abstract}
RESUMO - A pirólise de pneus inservíveis tem sido apontada como alternativa viável para produção de combustíveis a partir de resíduos. Embora o condensado obtido da pirólise de pneus possua algumas propriedades combustíveis dentro dos padrões técnicos requeridos, restrições ambientais exigem a redução de teor de enxofre aos níveis aceitáveis pela legislação. A dessulfurização por adsorção, baseada na remoção de compostos sulfurados através da adsorção em carvão ativado, é uma técnica promissora aplicada para reduzir o teor de enxofre de combustíveis. Este trabalho apresenta uma investigação experimental da remoção de compostos de enxofre da fração líquida obtida da pirólise de resíduos de pneus. O estudo avaliou o processo de dessulfuração do líquido da pirólise por meio de adsorção em carvão ativado, a fim de reduzir o teor de enxofre e manter conformidade com as exigências ambientais de forma a viabilizar sua utilização como combustível alternativo. Testes foram realizados para avaliar a taxa de adsorção de compostos de enxofre. Tiophene e dibenzotiofeno foram utilizados como padrão, devido a sua maior concentração em combustíveis convencionais. Os dados foram correlacionados através de isotermas de adsorção para ambos compostos-padrão de enxofre e compostos sulfurado presentes no condensado da pirolise. A redução do teor de enxofre foi avaliado por cromatografia líquida de alta eficiência (CLAE) e mostra uma redução gradual da concentração de compostos de enxofre com o tempo de adsorção, atingindo o equilíbrio até 5 dias.
\end{abstract}

\section{INTRODUÇÃO}

Inúmeros problemas ao meio ambiente são decorrentes do descarte de pneus inservíveis. Ao serem descartados incorretamente, pneus podem contaminar o solo, água e até mesmo afetar a saúde das pessoas. De acordo com Lagarinhos e Tenório (2008), a produção mundial de pneus foi de 1,32 bilhões em 2001. A Resolução do Conselho Nacional do Meio Ambiente (CONAMA) no 258/99 estabelece que os fabricantes tem total responsabilidade por seus pneus, desde a produção até o destino final.

Os pneus inservíveis são aqueles que não mais prestam para o processo de reforma (que tem como objetivo fazer com que o pneu possua rodagem adicional) e por isso, é necessária alguma alternativa para seu descarte correto (CONAMA, 1999). Para solucionar os problemas gerados pelo descarte incorreto de pneus, muitas tecnologias estão sendo propostas a fim de reduzir os impactos 
ambientais. A pirólise de pneus tem sido apontada como uma via promissora para o aproveitamento de pneus inservíveis e redução dos impactos causados pelo seu descarte. A pirólise de pneus produz uma fase líquida, resultante da condensação dos gases da pirólise, com elevado potencial para aplicação como combustível. Um dos principais problemas em utilizar o condensado da pirólise de pneus como combustível é a presença de compostos sulfurados. Tanto nos combustíveis convencionais quanto no condensado oriundo da pirólise de pneus, encontra-se grande quantidade de compostos sulfurados (Song e Ma, 2003). Uma vez que o teor de enxofre nos combustíveis deve respeita a regulamentação vigente, métodos de dessulfurização devem ser aplicados para a remoção de enxofre do líquido antes de sua aplicação.

A dessulfurização adsortiva vem ganhando muita importância como técnica para a redução do teor de enxofre nos combustíveis (SONG, 2003). A dessulfurização adsortiva remove os compostos em questão através da adsorção do componente na superfície de um sólido (material adsorvente). As propriedades dos materiais adsorventes (como área de superfície, porosidade, etc) são fundamentais para que este procedimento seja eficaz (ROUQUEROL et al., 1999). O presente trabalho tem como objetivo avaliar a remoção do teor de enxofre do condensado oriundo da pirólise de pneus inservíveis através da dessulfurização adsortiva utilizando o carvão ativado.

\section{METODOLOGIA EXPERIMENTAL}

Adsorção de compostos sulfurados em carvão ativado: Para avaliar a dessulfurização do condensado da pirólise de pneus, o estudo da adsorção de compostos sulfurados foi realizado em duas etapas. Na primeira etapa, foi avaliada a adsorção de compostos padrões de enxofre (tiofeno e dibenzotiofeno) a partir de soluções destes compostos em heptano. Foram preparadas soluções de concentração conhecida destes compostos e realizado o ensaio de adsorção ao longo do tempo. Na segunda etapa, foi avaliada a adsorção de compostos de enxofre, a partir do condensado. $\mathrm{O}$ estudo de adsorção de compostos sulfurados a partir de suas soluções ou a partir do condensado foi realizado em incubadora tipo shaker orbital (Figura 1), sob agitação de $100 \mathrm{rpm}$ e temperatura de $25^{\circ} \mathrm{C}$. Inicialmente, volumes pré-definidos $(200 \mathrm{~mL})$ das soluções orgânicas foram colocadas individualmente em diferentes frascos erlenmeyer de $250 \mathrm{~mL}$. Em seguida, foi adicionada 5 gramas de carvão previamente ativado, selado e rotulado.
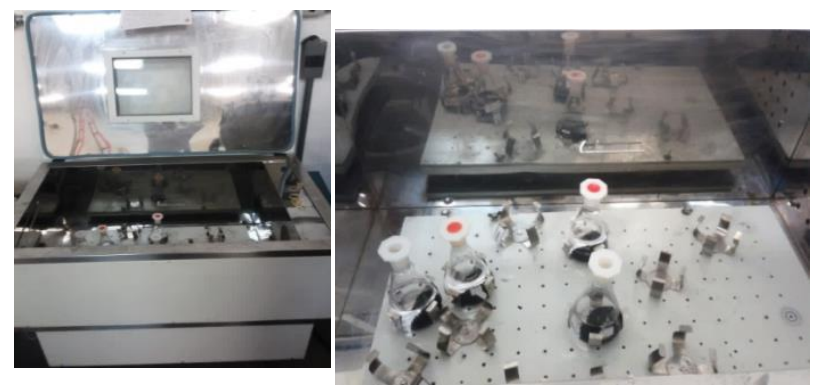

Figura 1 - Incubadora tipo shaker orbital.

Os frascos contendo as misturas foram então postas no shaker e em intervalos regulares de $24 \mathrm{~h}$, 
foi realizada a amostragem da solução e enviada para análise quantitativa para identificar a concentração do adsorbato presente. A remoção de enxofre da solução foi avaliada através da análise da quantidade de composto de enxofre removida da solução em função do tempo.

Analise quantitativa: Para quantificar a adsorção em fase líquida utilizou-se a cromatografia líquida de alta eficiência. Com este método foram projetadas curvas de calibração, as quais podem identificar a concentração desconhecida de uma amostra após a adsorção dos compostos conforme a área gerada pelo pico cromatográfico. Através dos valores obtidos pelos gráficos da cromatografia líquida de alta eficiência, obteve-se a curva de calibração para tiofeno e dibenzotiofeno (Figura 2 e 3 ).

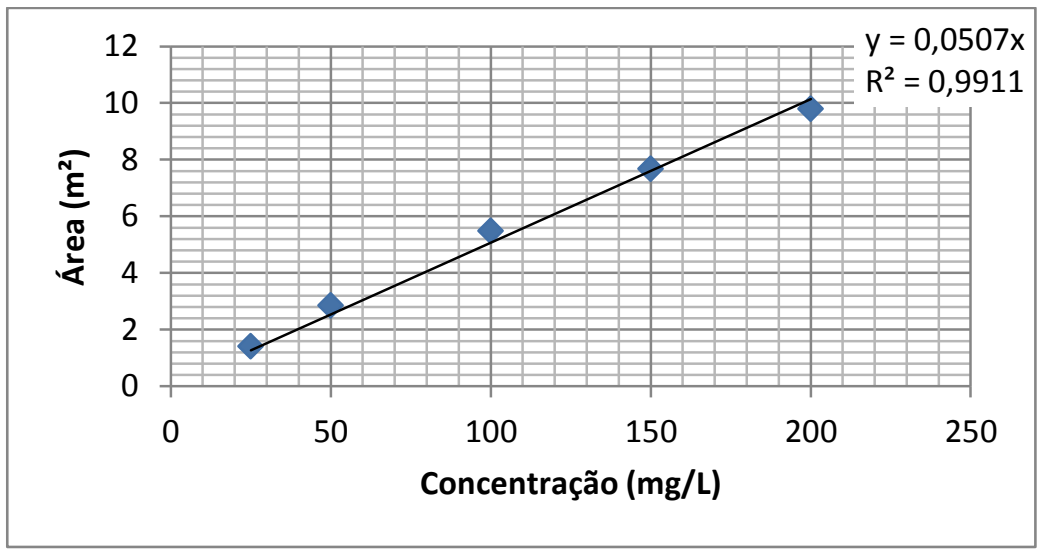

Figura 2 - Curva de calibração e equação da reta para tiofeno.

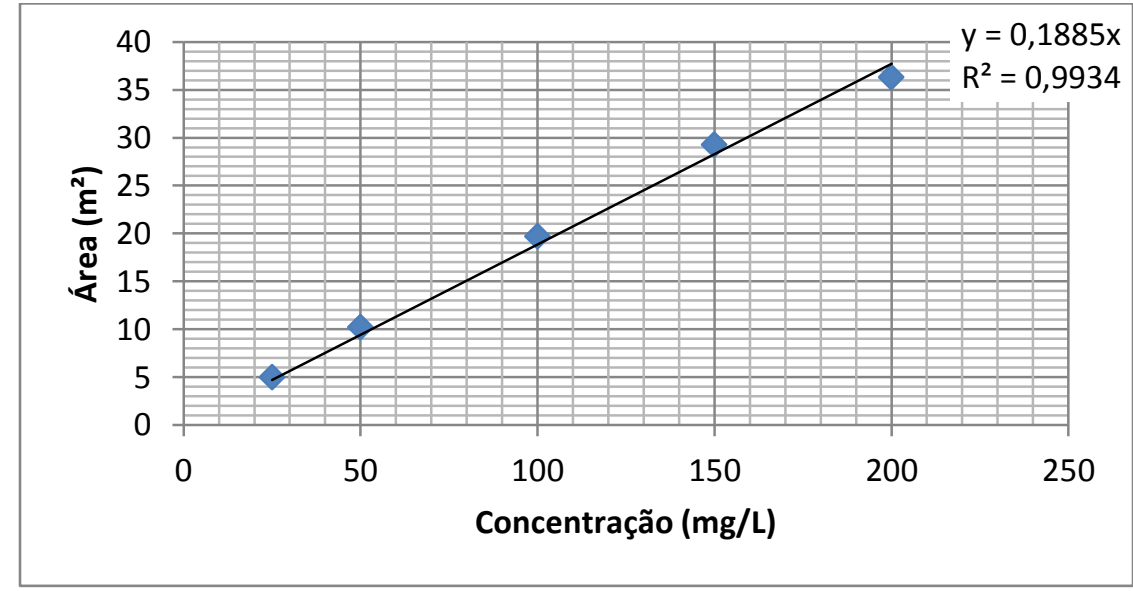

Figura 3 - Curva de calibração e equação da reta para dibenzotiofeno. 


\section{RESULTADOS E DISCUSSÃO}

Para o teste de adsorção da solução a partir de dibenzotiofeno, os resultados estão apresentados na Figura 4.

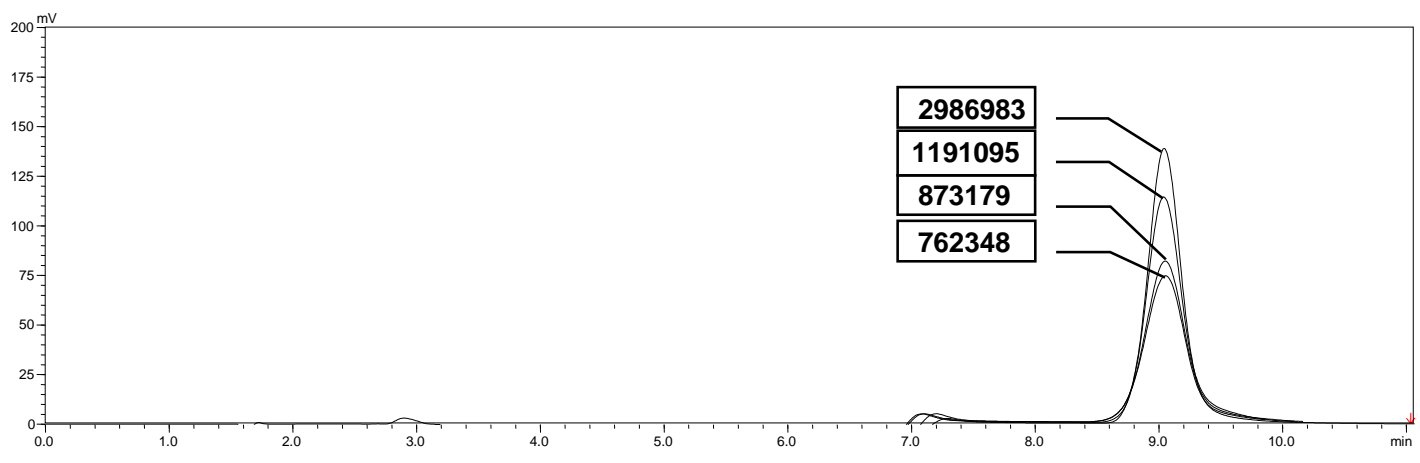

Figura 4 - Cromatogramas obtidos após a análise das alíquotas de dibenzotiofeno durante 4 dias.

A quantidade de soluto adsorvida foi determinada através da curva de calibração (figuras 2 e 3). A adsorção de dibenzotiofeno em carvão ativado durante 96 dias é descrita pela curva ilustrada na Figura 5. Os resultados mostram que, após 48 horas, a concentração de dibenzotiofeno em solução se reduz a valores inferior a $5 \mathrm{mg} / \mathrm{L}$.

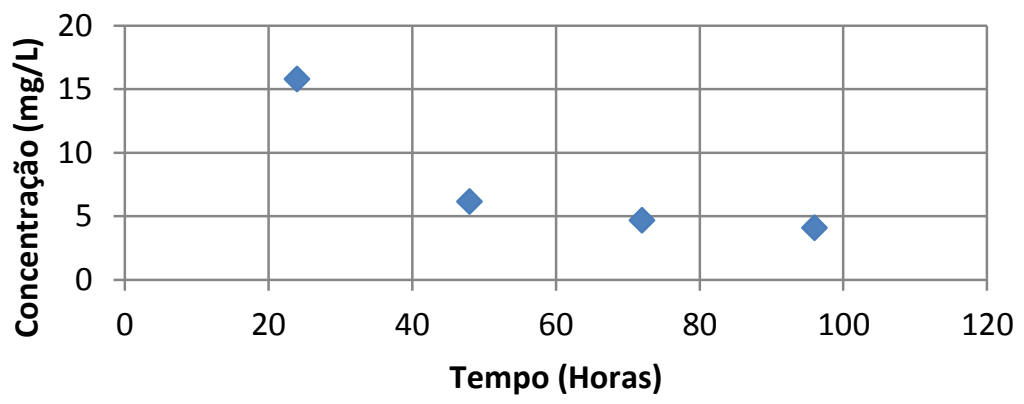

Figura 5 - Curva de adsorção de dibenzotiofeno.

Os testes realizados com tiofeno em concentrações variadas, não apresentaram resultados satisfatórios (ver Figura 6 e 7). 


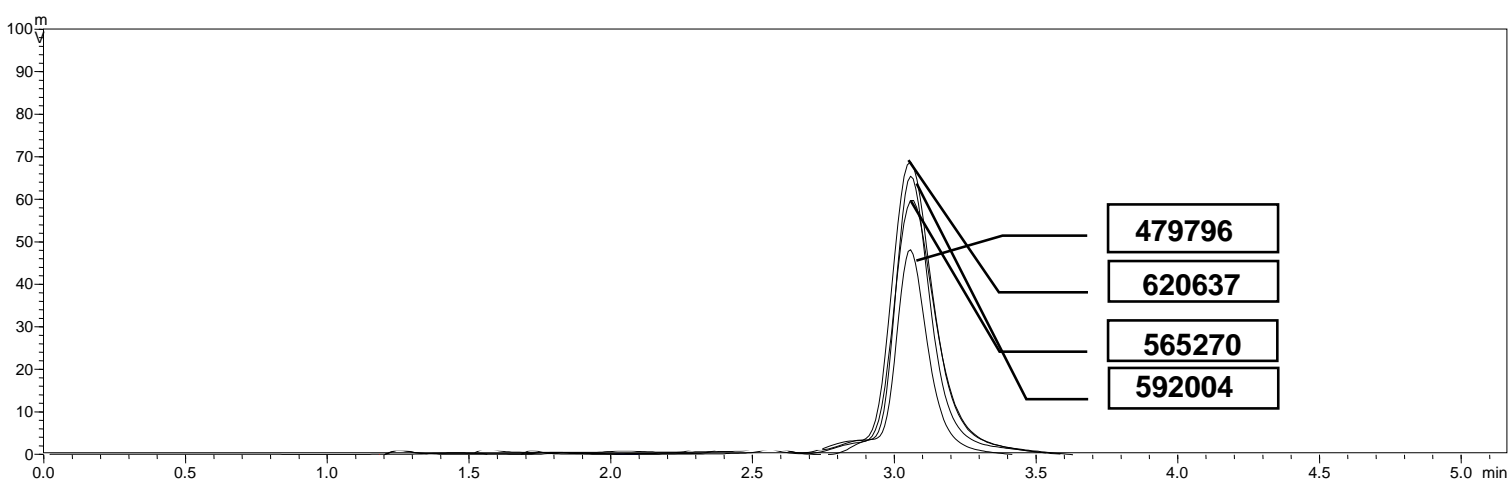

Figura 6 - Cromatogramas obtidos após a análise das alíquotas de tiofeno durante 4 dias.

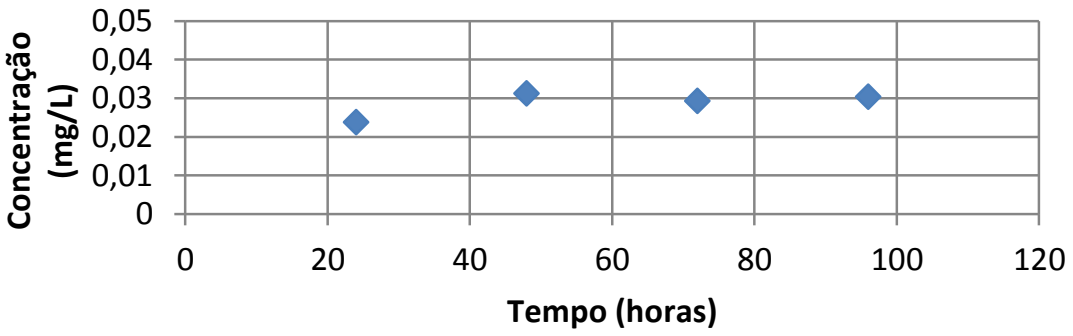

Figura 7 - Curva de adsorção de tiofeno.

Para o condensado oriundo da pirólise de pneus inservíveis (CPP) foi previamente realizado um teste de separação dos componentes sólidos que estavam nele contidos. Os correspondentes cromatogramas são apresentados nas figuras 8 e 9. Na avaliação cromatográfica do CPP, os compostos de interesse (tiofeno e dibenzotiofeno) foram adicionados ao condensado para potencializar a leitura do pico e a quantidade destes compostos foi determinada por diferença.

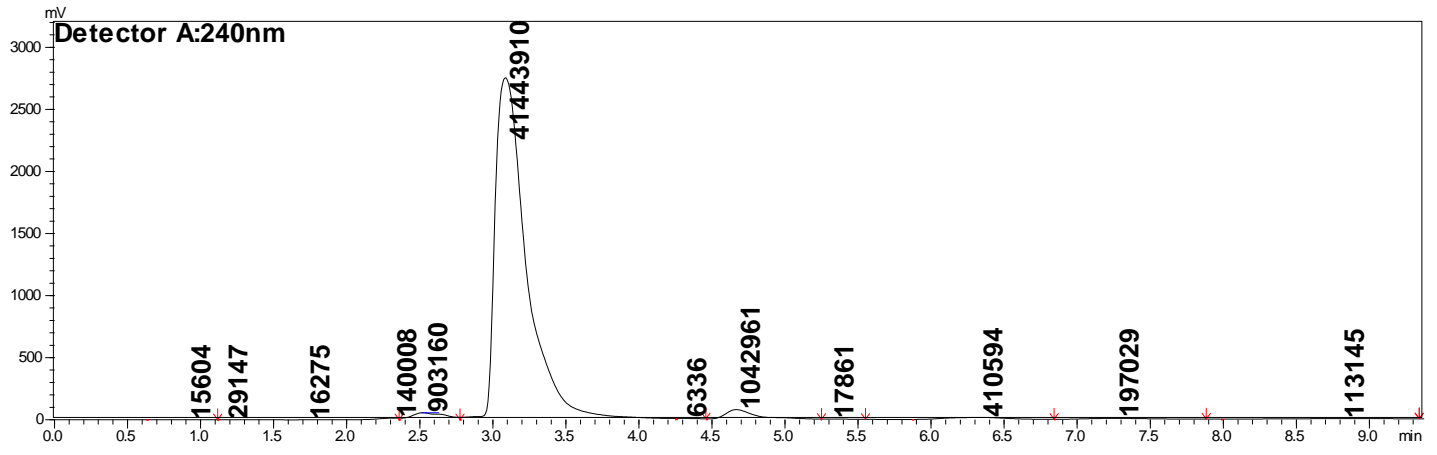

Figura 8. Cromatogramas obtidos após a análise das alíquotas de tiofeno no CPP durante 4 dias. 


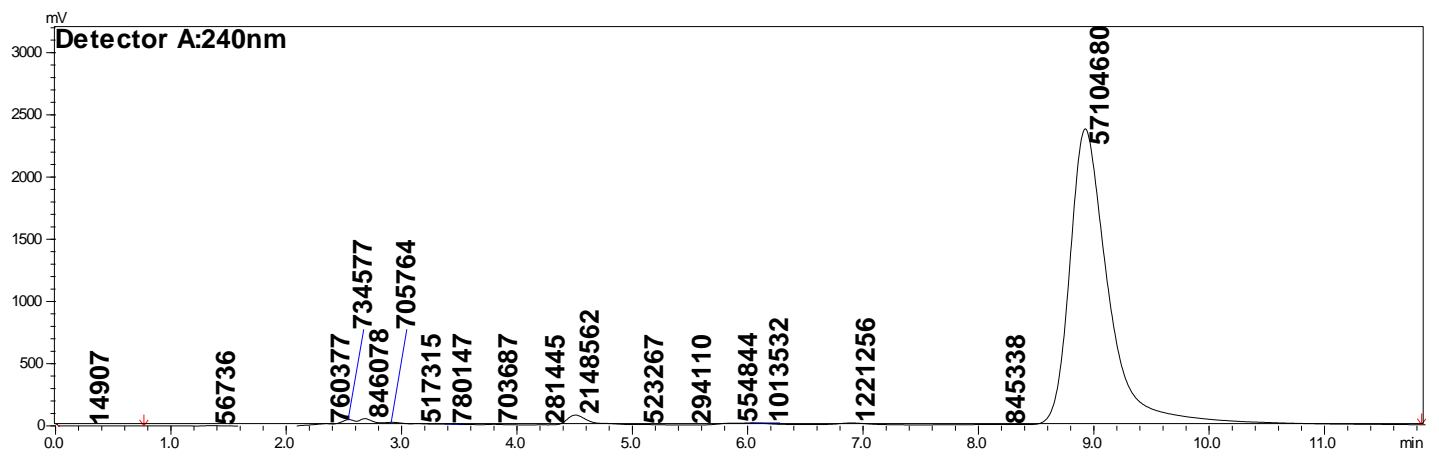

Figura 9. Cromatogramas obtidos após a análise das alíquotas de dibenzotiofeno no CPP durante 4 dias.

A análise cromatográfica do CPP mostra uma redução dos compostos em análise ao longo do tempo, indicando a adequação da dessufulrização adsortiva para a remoção de tiofeno e dibenzotiofeno do condensado da pirólise de pneus.

\section{CONCLUSÃO}

O condensado oriundo da pirólise tem em sua composição compostos de enxofre que para seu uso posterior é necessário sua remoção devido às normas ambientais vigentes. Esse processo de remoção foi realizado através da dessulfurização adsortiva usando carvão ativado como adsorvente.

Os resultados mostram que os compostos padrão podem ser removidos da solução por adsorção em carvão ativado. A redução da concentração é bastante significativa em um período de 5 dias para o composto de dibenzotiofeno, mostrando assim que a capacidade do carvão ativado nas condições utilizadas foi satisfatório para concentrações entre 6580 à 1316 ppm. Superior a esta concentração de 6580 ppm a curva de adsorção começou a falhar, resultando em pontos oscilantes, o que pode-se notar que o carvão saturou-se com a quantidade de soluto em questão. Em relação aos testes realizados com tiofeno, os resultados oscilaram e não foram satisfatórios. Resultados mostraram redução da concentração dos compostos no condensado da pirólise de pneus.

\section{REFERENCIAS}

CONAMA, Conselho Nacional do Meio Ambiente. Resolução n ${ }^{0}$ 258, 26 de agosto de 1999. Disponível em: <http://www.mma.gov.br/port/conama/res/res99/res25899.html> . Acesso em: 21 jan. 2014. 
LAGARINHOS, C. A. F., TENÓRIO, J. A. S. Tecnologias Utilizadas para a Reutilização, Reciclagem e Valorização Energética de Pneus no Brasil, v. 18, p. 106-118, 2008.

ROUQUEROL, F.; ROUQUEROL, J.; SING, K. Adsorption By Powders \& Porous Solids: Principles, Methodology And Applications, ed. 1, 1999.

SONG, C. An overview of new approaches to deep desulfurization for ultra-clean gasoline, diesel fuel and jet fuel, v. 86, p. 211-263, 2003.

SONG, C.; MA, X. New design approaches to ultra-clean diesel fuels by deep desulfurization and deep dearomatization, v. 41, p. 207-238, 2003. 